\title{
EFFECT OF FLOW COMPETITION ON INTERNAL THORACIC ARTERY GRAFT: POSTOPERATIVE VELOCIMETRIC AND ANGIOGRAPHIC STUDY
}

Tsuyoshi Shimizu, MD

Tetsuzo Hirayama, MD

Hiroyuki Suesada, MD

Katsusuke Ikeda, MD

Shigeki Ito, MD

Shin Ishimaru, MD
Objectives: To assess the effects of competitive blood flow on internal thoracic artery grafts, we investigated postoperative flow velocity characteristics and angiographic findings of the grafts with various grades of native coronary artery stenosis.

Methods: Fifty patients who had an internal thoracic artery graft to the left anterior descending artery underwent intravascular Doppler graft velocimetry during postoperative angiography. Patients were divided into 3 groups according to the grade of native coronary stenosis: group $\mathrm{H}$ (28 patients), $80 \%$ stenosis or greater; group M (16 patients), $60 \%$ to $79 \%$ stenosis; and group L (6 patients), $40 \%$ to $59 \%$ stenosis. Phasic flow velocity of the grafts was measured with an intravascular Doppler ultrasound-tipped guide wire during angiography. Graft flow volume was calculated from the diameter and the average peak velocity.

Results: Average peak velocity (group H, $27.1 \pm 8.6 \mathrm{~cm} / \mathrm{s}$; group M, $16.9 \pm$ $3.9 \mathrm{~cm} / \mathrm{s}$; group L, $7.2 \pm 3.7 \mathrm{~cm} / \mathrm{s}$ ), distal graft diameter (group H, $2.27 \pm$ $0.23 \mathrm{~mm}$; group M, $2.00 \pm 0.28 \mathrm{~mm}$; group L, $1.07 \pm 0.27 \mathrm{~mm}$ ), and calculated graft flow volume (group $\mathrm{H}, 33.1 \pm 12.0 \mathrm{~mL} / \mathrm{min}$; group $\mathrm{M}, 16.2 \pm 5.8$ $\mathrm{mL} / \mathrm{min}$; group $\mathrm{L}, 2.3 \pm 2.0 \mathrm{~mL} / \mathrm{min}$ ) significantly differed among the 3 groups. Graft flow in diastole and systole also differed among the 3 groups.

Conclusions: Competitive blood flow reduces internal thoracic artery graft flow and diameter according to the grade of the native coronary artery stenosis. These data suggest that grafting the internal thoracic artery to the coronary artery with stenosis of a low grade can cause graft atrophy and failure. (J Thorac Cardiovasc Surg 2000;120:459-65)
$T_{\text {hem }}^{\text {he }}$ he internal thoracic artery (ITA) has been recognized to be the optimal conduit on the basis of superior patency rates and clinical performance. ${ }^{1,2}$ Despite beneficial results of the ITA graft, grafting to the coronary artery with proximal stenosis of low grade is a controversial issue. It has been reported that competitive blood flow from the native coronary artery affects ITA graft morphology ${ }^{3}$ and causes graft

From Department of Surgery II, Tokyo Medical University, Shinjuku-ku, Tokyo, Japan.

Received for publication Oct 6, 1999; revisions requested Dec 13, 1999; revisions received April 10, 2000; accepted for publication April 21, 2000.

Address for reprints: Tsuyoshi Shimizu, MD, Cardiothoracic Surgery, The St George Hospital, Gray St, Kogarah, NSW 2217, Australia (E-mail: t-shimiz@edu1.tokyo-med.ac.jp).

Copyright (C) 2000 by The American Association for Thoracic Surgery

0022-5223/2000 $\$ 12.00+0 \quad \mathbf{1 2 / 1 / 1 0 8 1 6 6}$

doi:10.1067/mtc.2000.108166 failure 4 or occlusion. ${ }^{3,5}$ On the other hand, Cosgrove and colleagues ${ }^{6}$ reported that the 1 - to 2 -year patency rates of the ITA were similar for grafts placed to coronary arteries with less than $50 \%$ stenosis compared with arteries with greater than $50 \%$ stenosis. Kawasuji and coworkers ${ }^{7}$ advocated ITA grafting to the left anterior descending artery (LAD) with $50 \%$ proximal stenosis or less, because the ITA graft flow in diastole was independent of the grades of native coronary artery stenosis in their intraoperative phasic flow study. Furthermore, some experimental studies showed that ITA graft flow volume was maintained above in situ levels even when the ITA was grafted to a completely patent coronary artery.., 9

An intravascular Doppler ultrasound-tipped guide wire, developed as a coronary angioplasty guide wire, has been used for analysis of phasic flow velocity of ITA grafts during postoperative angiography. ${ }^{10-13} \mathrm{By}$ means of this technique, phasic flow velocity can be 
Table I. Baseline characteristics

\begin{tabular}{lccc}
\hline & Group H $(80 \%-100 \%$ stenosis) & Group M (60\%-79\% stenosis) & Group L (40\%-59\% stenosis) \\
\hline No. of patients & 28 & 16 & 6 \\
Age (y) & $64 \pm 7$ & $68 \pm 7$ & $63 \pm 11$ \\
Female patients & 5 & 1 & 0 \\
Body surface area $\left(\mathrm{m}^{2}\right)^{*}$ & $1.59 \pm 0.13$ & $1.58 \pm 0.11$ & $1.53 \pm 0.09$ \\
Duration from operation to study $(\mathrm{wk})^{\dagger}$ & $29(3-87)$ & $29(3-63)$ & $25(4-59)$ \\
No. of bypass grafts/patient & $2.4 \pm 0.6$ & $2.6 \pm 0.6$ & 3 \\
Left main disease & 3 & 2 & 0 \\
Previous myocardial infarction & 10 & 4 & 2 \\
Anteroseptal myocardial infarction & 5 & 0 & 0 \\
Left ventricular ejection fraction $(\%)^{\dagger}$ & $61(50-68)$ & $66(57-64)$ & $60(50-65)$ \\
Free flow of ITA (mL/min) & $89(56-101)$ & $96(50-100)$ & \\
\hline
\end{tabular}

*Data are expressed as mean \pm standard deviation.

Data are expressed as median and 25 th and 75 th percentiles.

accurately quantified in the ITA grafts under various competitive flow conditions.

The purpose of this study was to investigate the effect of competitive blood flow on ITA grafts to the LAD with various grades of proximal stenosis with the use of Doppler guide wire velocimetry and quantitative angiography after coronary artery bypass grafting (CABG).

\section{Patients and methods}

Seventy-three patients underwent elective CABG in our institutes (Tokyo Medical University Hospital and Tanashi Daiichi Hospital), and 51 patients who had previously undergone CABG were referred to our institutes for evaluation of graft patency between 1996 and 1997. Of these 124 patients, 96 patients underwent ITA grafting to the LAD. Of these patients, 14 patients who also had grafting to the diagonal branch of the LAD (with a saphenous vein graft, 13 patients; with an inferior epigastric artery graft, 1 patient) were excluded for the effect of flow competition with the other grafts. Two patients who had a composite $\mathrm{T}$ graft with the ITA and the inferior epigastric artery graft were also excluded from this study. Of the remaining 80 patients, 62 patients underwent angiography; however, 7 of these patients were excluded from this study because of difficulty in introducing the guide wire into the anastomotic site, 3 were excluded because of anastomotic stenosis, and 2 were excluded because of graft occlusion. The final study group consisted of 50 symptomfree patients in the context of a postoperative angiographic follow-up study at intervals from 2 weeks to 5 years (median 25 weeks) after the operation.

Patient age ranged from 50 to 78 years (mean 65 years). The left ITA was examined in 49 patients and the right ITA in 1 patient. All but 1 patient received 1 to 3 additional CABGs (saphenous vein or gastroepiploic artery, with or without another ITA), and the mean number of CABGs was $2.6 \pm 0.6$ (mean \pm standard deviation) per patient. All patients gave informed consent to be included in this study.
Coronary angiography and flow velocity measurement. Coronary angiography was performed by the standard femoral approach. After ITA angiography, a $5 \mathrm{~F}$ or $6 \mathrm{~F}$ catheter was positioned in the origin of the ITA. A 0.018-inch 12$\mathrm{MHz}$ Doppler guide wire (FloWire; Cardiometrics, Inc, Mountain View, Calif) was connected to a velocimeter (FloMap; Cardiometrics), advanced through the catheter into the ITA graft, and introduced into the anastomotic site. Phasic flow velocity was recorded in the distal portion of the ITA graft. The graft diameter at the points of flow velocity measurements and the percent stenosis of the native coronary artery diameter were determined by angiography with an automated edge-contour detection system (Cardio 500; Kontron Electronic AG, Eching, Germany).

Total, diastolic, and systolic flow volume were calculated by means of the following equations, as previously reported. ${ }^{11,14}$

$$
\begin{gathered}
\text { Total flow volume }(\mathrm{Q})=0.5 \times \mathrm{APV} \times \pi(\mathrm{D} / 2)^{2} \\
\text { Diastolic flow volume }=\mathrm{Q} \times \mathrm{DVi} /(\mathrm{DVi}+\mathrm{SVi}) \\
\text { Systolic flow volume }=\mathrm{Q} \times \mathrm{SVi} /(\mathrm{DVi}+\mathrm{SVi})
\end{gathered}
$$

where APV = time-averaged peak velocity, $\mathrm{D}=$ graft diameter, $\mathrm{DVi}=$ diastolic time velocity integral, and $\mathrm{SVi}=$ systolic time velocity integral.

Patient classifications. Patients were divided into 3 groups according to the grade of the proximal LAD or left main coronary artery stenosis at the time of the study: group $\mathrm{H}(28$ patients), $80 \%$ stenosis or greater; group M (16 patients), $60 \%$ to $79 \%$ stenosis; and group L (6 patients), $40 \%$ to $59 \%$ stenosis.

Statistical analysis. In the analysis of continuous data among the 3 groups, statistical evaluation was performed by the Steel-Dwass test. In the analysis of rank data, statistical evaluation was performed by the Kruskal-Wallis test.

\section{Results}

Baseline characteristics are summarized in Table I. No significant differences among the 3 groups were observed in terms of age, sex, body surface area, time 
Table II. Angiographic findings

\begin{tabular}{lccc}
\hline & Group $H$ & Group $M$ & Group L \\
\hline Distal LAD flow patterns & & \\
$\quad$ Graft dependent & & & 0 \\
$\quad$ Balanced & 24 & 6 & 0 \\
$\quad$ Native dependent & 4 & 2 & 6 \\
Diameter (mm) & 0 & $2.74 \pm 0.41^{\S}$ & $1.98 \pm 0.41$ \\
$\quad$ Proximal ITA graft & & $2.00 \pm 0.28^{\S}$ & $1.07 \pm 0.27$ \\
$\quad$ Distal ITA graft & $2.89 \pm 0.32^{\S}$ & $1.80 \pm 0.27$ & $2.06 \pm 0.38$ \\
$\quad$ Native coronary artery & & & \\
Stenosis of native coronary artery $(\%)^{\ddagger}$ & $1.27 \pm 0.23^{\S}$ & $71(67-74)^{\S}$ & $45(41-50)$ \\
\hline
\end{tabular}

$L A D$, Left anterior descending artery; ITA, internal thoracic artery.

${ }^{*} P<.0001$ among the 3 groups.

Data are expressed as mean \pm standard deviation

Data are expressed as median and 25 th and 75 th percentiles.

$\S_{P}<.01$ versus group $\mathrm{L}$.

$\| P<.01$ versus group $\mathrm{M}$.

from operation to study, left main coronary artery disease, history of myocardial infarction, left ventricular ejection fraction, and intraoperative free flow of the ITA grafts.

Angiographic findings. ITA angiography opacified the entire graft and distal LAD in all the patients, and all the ITA-LAD anastomoses were normal. According to left coronary angiography, distal LAD flow patterns were classified into 3 patterns: native-dominant flow, in which the distal LAD was well visualized from the native coronary injection; balanced flow, in which the distal LAD was visualized faintly; and graft-dominant flow, in which the distal LAD was not visualized from the native coronary injection. The distribution of these patterns significantly differed among the 3 groups $(P<$ .0001) (Table II).

The proximal graft diameter in group L was significantly smaller than that in group $\mathrm{H}$ and group $\mathrm{M}$, but it did not differ between group $\mathrm{H}$ and group $\mathrm{M}$. The distal graft diameter significantly differed among the 3 groups (Table II). In group L, inflow of contrast medium from the native coronary artery up to the middle to proximal portion of the graft was observed. Of 6 patients in group L, 3 patients had the "string sign," defined as diffuse narrowing with a diameter less than $1.0 \mathrm{~mm}$ from 12 to 33 months after the operation. In these 3 patients, angiography performed 3 to 4 weeks postoperatively did not show the string sign but did showed mild to moderate graft diameter reduction and normal left ITA-LAD anastomosis.

Phasic flow velocity pattern. In group $\mathrm{H}$, typical biphasic velocity spectra with diastolic predominance were obtained in the distal portion of the ITA graft (Fig $1, A$ ). In all but 1 patient of group $\mathrm{M}$ and 7 patients of group $\mathrm{H}$, flow velocity spectra showed a retrograde spike in early systole (Fig 1, B). In all of the patients in group L, flow velocity spectra showed retrograde flow (flow reversal) in systole and lower antegrade peak flow in diastole (Fig 1,C).

Flow velocity data and calculated flow volume. Average peak velocity significantly differed among the 3 groups, as did average diastolic and systolic peak velocity. Diastolic/systolic velocity ratio was higher in group L than in group H (Table III).

Calculated total flow volume significantly differed among the 3 groups (group H, $33.1 \pm 12.0 \mathrm{~mL} / \mathrm{min}$; group $\mathrm{M}, 16.2 \pm 5.8 \mathrm{~mL} / \mathrm{min}$; group $\mathrm{L}, 2.3 \pm 2.0$ $\mathrm{mL} / \mathrm{min}$ ). Flow volume in diastole and systole also differed among the 3 groups (Fig 2).

\section{Discussion}

Flow measurements of the ITA graft have been performed intraoperatively and postoperatively with various techniques to identify the hemodynamic performance of the ITA graft. ${ }^{7}, 10,12,13,15$ In group $\mathrm{H}$, the flow velocity was similar to that of previous reports. Considering the small body surface area of the patients in this study, the calculated flow volume and the graft diameter were also similar to those of previous reports. Typical biphasic velocity spectra, which represent coronary circulation, were observed in these grafts.

In contrast, distal graft diameter in group $\mathrm{M}$ was smaller than in group H. Seki and his colleagues ${ }^{3}$ demonstrated the flow adaptability of the ITA graft responding to the flow demand of the recipient coronary artery as a result of the correlation between the ITA graft diameter and the native coronary artery stenosis. In our study, graft flow velocity and calculated flow volume, as well as graft diameter, were lower in group $\mathrm{M}$ than in group $\mathrm{H}$. With regard to analysis of 


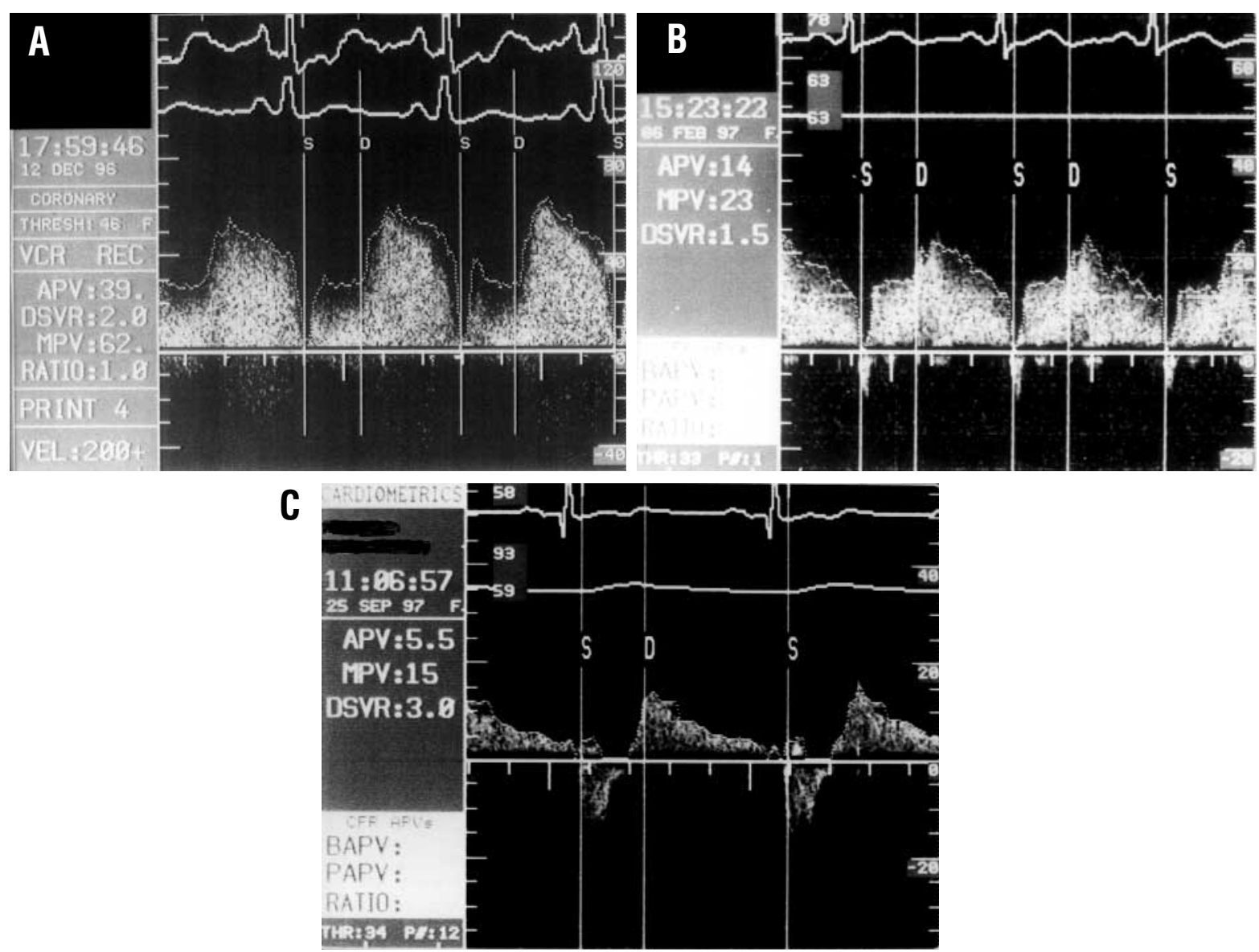

Fig 1. A, Flow velocity spectra acquired at the distal portion of the ITA graft to the LAD artery with $100 \%$ proximal stenosis. The waveform was biphasic and diastolic flow was predominant. No retrograde flow was observed. B, Flow velocity spectra acquired at the distal portion of the ITA graft to the LAD artery with $71 \%$ stenosis. In early systole, a retrograde spike was observed. C, Flow velocity spectra acquired at the distal portion of the ITA graft to the LAD artery with $48 \%$ stenosis. A swinging flow pattern (systolic retrograde and diastolic antegrade flow) was observed. Note that the calibrations of flow velocity differ among the 3 figures. APV, Time-averaged peak velocity; $M P V$, maximum peak velocity; $D S V R$, diastolic/systolic velocity ratio; $S$, systole; $D$, diastole.

the phasic flow velocity, diastolic and systolic flow differed between the 2 groups. In early systole, retrograde flow (flow reversal) was observed in most of the grafts in group M. This finding, which has been reported by other authors, ${ }^{11,13,16}$ could be attributed to a delay in the pressure wave of the ITA grafts ${ }^{17}$ under competitive flow conditions. The pressure wave reaches the ITA after reaching the LAD, which is much closer to the aorta $^{16}$; however, the retrograde flow (flow reversal) in most of the grafts in group $\mathrm{M}$ was represented by narrow and sharp contours, which did not appear to be hemodynamically significant.

Furthermore, graft diameter was much smaller in group $\mathrm{L}$, and some patients showed the string sign. Consequently, mean calculated flow volume was nearly
$10 \%$ of that in group $\mathrm{H}$. Mean flow velocity in these patients was, however, a quarter of that in group $\mathrm{H}$. These results suggested that graft diameter reduction adapting flow demand could be a contributory factor to maintaining graft flow velocity at a relatively higher level.

In the phasic velocity pattern, diastolic flow of the ITA considerably diminished; on the other hand, systolic retrograde flow appeared to be more apparent. This finding can be called the swinging flow pattern (oscillating flow pattern ${ }^{16}$ or to-and-fro pattern ${ }^{13}$ ). In 1 patient having the string sign, hyperemia was induced by $10 \mathrm{mg}$ of papaverine hydrochloride injection into the graft during the examination. The swinging flow pattern was observed at rest, and the average peak velocity of this graft was $5.5 \mathrm{~cm} / \mathrm{s}$. The average peak 
Table III. Phasic flow velocity data

\begin{tabular}{|c|c|c|c|}
\hline & Group $H$ & Group M & Group L \\
\hline Time-averaged peak velocity $(\mathrm{cm} / \mathrm{s})^{*}$ & $27.1 \pm 8.6^{\ddagger \S}$ & $16.9 \pm 3.9^{\ddagger}$ & $7.2 \pm 3.7$ \\
\hline Time-averaged diastolic peak velocity $(\mathrm{cm} / \mathrm{s})^{*}$ & $38.1 \pm 13.2^{\ddagger \S}$ & $25.5 \pm 9.7^{\mathbb{I I}}$ & $11.3 \pm 7.3$ \\
\hline Time-averaged systolic peak velocity $(\mathrm{cm} / \mathrm{s})^{*}$ & $17.3 \pm 7.2^{ \pm \|}$ & $11.4 \pm 4.5^{\ddagger}$ & $3.3 \pm 2.6$ \\
\hline Diastolic/systolic velocity ratio ${ }^{\dagger}$ & $2.05(1.84-2.65)^{\mathbb{I}}$ & $2.34(1.89-3.38)$ & $3.01(2.98-3.60)$ \\
\hline Time velocity integral $(\mathrm{U})^{*}$ & $21.2 \pm 5.9 \ddagger 8$ & $13.4 \pm 3.4^{\ddagger}$ & $6.1 \pm 2.9$ \\
\hline Diastolic time velocity integral $(\mathrm{U})^{*}$ & $16.7 \pm 4.5^{\ddagger \S}$ & $10.4 \pm 3.2^{\ddagger}$ & $5.1 \pm 2.4$ \\
\hline Systolic time velocity integral $(\mathrm{U})^{*}$ & $4.5 \pm 1.8^{\ddagger \S}$ & $2.9 \pm 1.2^{\ddagger}$ & $0.9 \pm 0.6$ \\
\hline Diastolic/systolic time velocity integral ratio ${ }^{\dagger}$ & $3.46(3.02-4.81)$ & $3.49(2.91-5.68)$ & $5.01(3.96-6.05)$ \\
\hline
\end{tabular}

*Data are expressed as mean \pm standard deviation.

Data are expressed as median and 25 th and 75 th percentiles.

${ }^{\ddagger} P<.01$ versus group L.

$\S_{P}<.01$ versus group $\mathrm{M}$.

$\|_{P}<.05$ versus group $\mathrm{M}$.

II $P<.05$ versus group $\mathrm{L}$.

velocity increased during hyperemia up to $15 \mathrm{~cm} / \mathrm{s}$. The calculated flow volume of this graft was approximately $1 \mathrm{~mL} / \mathrm{min}$ at rest and $3 \mathrm{~mL} / \mathrm{min}$ during hyperemia. Although such grafts have little hemodynamic significance, this swinging flow pattern could provide a beneficial effect on graft patency under competitive flow conditions. In the graft showing the string sign, this flow pattern could last and anatomic patency could be maintained while the diastolic flow of the ITA graft increased during exercise or hyperemia. ${ }^{13}$ This condition is not an absolute but an actual nonfunctioning stage; in other words, it is nearing no-flow patency.

Graft narrowing due to flow competition is generally reversible as a result of progression of the native coronary artery stenosis. However, we could not advocate prophylactic ITA grafting to the almost normal LAD, because it is unknown how long the anatomic patency of the nonfunctioning ITA graft can be maintained. When diastolic flow of the graft does not increase during exercise, the graft will become an absolute nonfunctioning graft and the swinging flow pattern will not be maintained for a long time. We performed ITA grafting to the LAD with $50 \%$ stenosis preoperatively and performed angiography 4 weeks after the operation. Angiography showed diffuse narrowing of the ITA with $42 \%$ stenosis of the LAD; otherwise, the anastomosis was normal. Doppler guide wire velocimetry showed the swinging flow pattern and decreased average peak velocity $(4.6 \mathrm{~cm} / \mathrm{s})$. One year after the first postoperative angiogram, total occlusion of this graft with 33\% diameter stenosis of the LAD was confirmed. Seki and his colleagues ${ }^{3}$ reported that 4 of 5 patients with ITA graft occlusion also had 50\% or less LAD stenosis, and myocardial imaging did not reveal ischemia.
Although restoration of ITA graft patency has been reported after apparent occlusion attributed to competitive flow from the native coronary artery, ${ }^{18,19}$ inflammation might have caused apparent temporary graft occlusion when the native coronary stenosis was $80 \%$ to $85 \%$ or more in the above cases. Diameter stenosis of $80 \%$ or more could not produce the string sign of the ITA graft. From our point of view, the string sign would rarely develop in an ITA graft to an LAD with more than $60 \%$ stenosis. Siebenmann and associates ${ }^{20}$ analyzed 10 cases of ITA string sign and found that the stenosis of the vessel bypassed with the narrowed graft was $50 \%$ or less at reangiography in all cases. Seki and his colleagues $^{3}$ also reported that of 9 patients who exhibited the string sign, 8 patients had 50\% LAD stenosis or less on postoperative angiography. Hashimoto and associates ${ }^{4}$ suggested that $60 \%$ stenosis in the native coronary artery could be a watershed for graft patency, and $50 \%$ stenosis might be too low as a criterion for in situ arterial bypass grafting.

Despite the low ITA graft flow under competitive flow conditions, we would advocate ITA rather than saphenous vein or other arterial conduits for grafting to the LAD with lower grade but significant stenosis because of the following reasons. First, atherosclerosis is much more common in the saphenous vein graft than in the ITA graft. ${ }^{21}$ Second, as flow velocity of the saphenous vein graft is lower than that of the ITA graft, ${ }^{12,22}$ the graft might become occluded when the coronary flow demand was minimal. Third, other arterial conduits, such as the gastroepiploic artery, radial artery, and inferior epigastric artery, are unfavorable for grafting to the coronary artery with lower grade stenosis. 23,24 


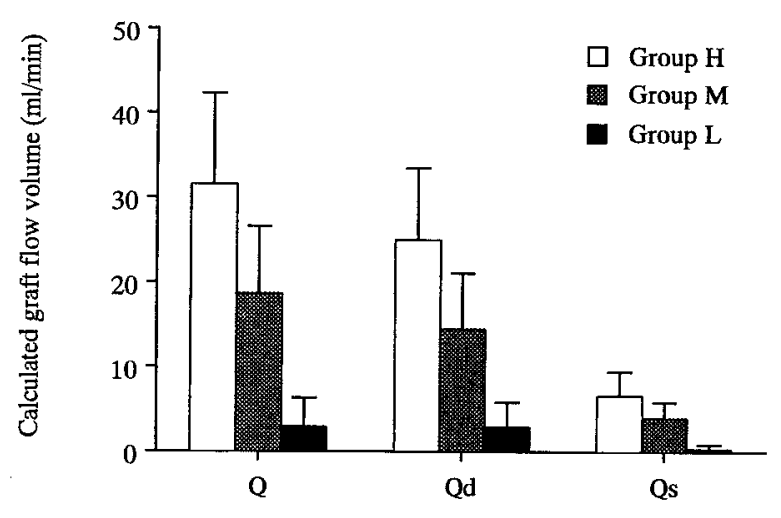

Fig 2. Calculated total $(Q)$, diastolic $(Q d)$, and systolic $(Q s)$ graft flow volume of the ITA grafts significantly differed among the 3 groups $(P<.01$ between group $\mathrm{H}$ and group $\mathrm{L}$; $P<.01$ between group $\mathrm{H}$ and group $\mathrm{M} ; P<.01$ between group $\mathrm{M}$ and group L). Data are expressed as mean, and error bars represent standard deviation.

In our study, the grade of the native coronary stenosis obviously affected the ITA graft flow. Nevertheless, the degree of coronary stenosis to keep the ITA graft functioning could not be accurately defined because the percent of coronary artery stenosis that would be hemodynamically significant has not yet been determined. It has been reported that percent diameter stenosis is not necessarily the best predictor of hemodynamic significance. ${ }^{25,26}$ However, visually or quantitatively estimated percent diameter stenosis in coronary angiography is widely accepted as a useful measure of the severity of coronary artery disease. Moreover, other investigations ${ }^{27-29}$ suggested that its cutoff value for significant coronary artery lesion ranged from $40 \%$ to $60 \%$ diameter stenosis. In our opinion, when the lesion is not significant, the ITA graft will not maintain its functional patency, and the cutoff value of the lesion to keep the ITA graft functionally patent also ranges from $40 \%$ to $60 \%$ diameter stenosis.

In conclusion, flow and diameter of the ITA graft are reduced in response to the competitive blood flow from the native coronary artery after CABG. These data suggest that grafting the ITA to the coronary artery with lower-grade stenosis can cause graft atrophy, failure, and occlusion. Therefore, prophylactic ITA grafting to the normal coronary artery is not recommended, but flow characteristics of the ITA grafts might be potential contributory factors in the patency of grafts to the coronary artery with lower grade but significant stenosis.
We are grateful to Professor J. Patrick Barron for his review of this manuscript and to Professor Tatsushi Itoh for advice on statistics.

\section{REFERENCES}

1. Barner HB, Standeven JW, Reese J. Twelve-year experience with internal mammary artery for coronary artery bypass. J Thorac Cardiovasc Surg 1985;90:668-75.

2. Loop FD, Lytle BW, Cosgrove DM, Stewart RW, Goormastic M, Williams GW, et al. Influence of the internal-mammary-artery graft on 10-year survival and other cardiac events. N Engl J Med 1986;314:1-6.

3. Seki T, Kitamura S, Kawachi K, Morita R, Kawata T, Mizuguchi $\mathrm{K}$, et al. A quantitative study of postoperative luminal narrowing of the internal thoracic artery graft in coronary artery bypass surgery. J Thorac Cardiovasc Surg 1992;104:1532-8.

4. Hashimoto H, Isshiki T, Ikari Y, Hara K, Saeki F, Tamura T, et al. Effects of competitive blood flow on arterial graft patency and diameter: medium-term postoperative follow-up. J Thorac Cardiovasc Surg 1996;111:399-407.

5. Ivert T, Huttenen K, Laudou C, Björk VO. Angiographic studies of internal mammary artery grafts 11 year after coronary artery bypass grafting. J Thorac Cardiovasc Surg 1988;96:1-12.

6. Cosgrove DM, Loop FD, Saunders CL, Lytle BW, Kramer JR. Should coronary arteries with less than fifty percent stenosis be bypassed? J Thorac Cardiovasc Surg 1981;82:520-30.

7. Kawasuji M, Sakakibara N, Takemura H, Tedoriya T, Ushijima T, Watanabe Y. Is internal thoracic artery grafting suitable for a moderately stenotic coronary artery? J Thorac Cardiovasc Surg 1996;112:253-9.

8. Spence PA, Lust RM, Zeri RS, Jolly SR, Mehta PM, Otaki M, et al. Competitive flow from a fully patent coronary artery does not limit acute mammary graft flow. Ann Thorac Surg 1992;54:21-6.

9. Lust RM, Zeri RS, Spence PA, Hopson SB, Sun YS, Otaki M, et al. Effect of chronic native flow competition on internal thoracic artery grafts. Ann Thorac Surg 1994;57:45-50.

10. Gurne O, Chenu P, Polidori C, Louagie Y, Buche M, Haxhe JP, et al. Functional evaluation of internal mammary artery bypass grafts in the early and late postoperative periods. J Am Coll Cardiol 1995;25:1120-8.

11. Nasu M, Akasaka T, Okazaki T, Shinkai M, Fujiwara H, Sono $\mathrm{J}$, et al. Postoperative flow characteristics of left internal thoracic artery grafts. Ann Thorac Surg 1995;59:154-61; discussion 161-2.

12. Bach RG, Kern MJ, Donohue TJ, Aguirre FV, Caracciolo EA. Comparison of phasic blood flow velocity characteristics of arterial and venous coronary artery bypass conduits. Circulation 1993;25:640-7.

13. Akasaka T, Yoshida K, Hozumi T, Takagi T, Kaji S, Kawamoto T, et al. Flow dynamics of angiographically no-flow patent internal mammary artery grafts. J Am Coll Cardiol 1998;31:1049-56.

14. Doucette JW, Corl PD, Payne HM, Flynn AE, Goto M, Nassi M, et al. Validation of a Doppler guide wire for intravascular measurement of coronary artery flow velocity. Circulation 1992;85:1899-911.

15. Canver CC, Cooler SD, Murray EL, Nichols RD, Heisey DM. Clinical importance of measuring coronary graft flows in the revascularized heart: Ultrasonic or electromagnetic? J Cardiovasc Surg 1997;38:211-5. 
16. Pagni S, Storey J, Ballen J, Montgomery W, Chiang BY, Etoch S, et al. ITA versus SVG: a comparison of instantaneous pressure and flow dynamics during competitive flow. Eur J Cardiothorac Surg 1997;11:1086-92.

17. Tedoriya T, Kawasuji M, Ueyama K, Sakakibara N, Takemura H, Watanabe Y. Physiologic characteristics of coronary artery bypass grafts. Ann Thorac Surg 1993;56:951-6.

18. Dincer B, Barner HB. The "occluded" internal mammary artery graft: restoration of patency after apparent occlusion associated with progression of coronary disease. J Thorac Cardiovasc Surg 1983;85:318-20.

19. Aris A, Borras X, Ramio J. Patency of internal mammary artery grafts in no-flow situations. J Thorac Cardiovasc Surg 1987;93:62-4.

20. Siebenmann R, Egloff L, Hirzel H, Rothlin M, Studer M, Tartini R. The internal mammary artery 'string phenomenon': analysis of 10 cases. Eur J Cardiothorac Surg 1993;7:235-8.

21. Lytle BW, Loop FD, Cosgrove DM, Ratliff NB, Easley K, Taylor PC. Long-term (5 to 12 years) serial studies of internal mammary artery and saphenous vein coronary bypass grafts. J Thorac Cardiovasc Surg 1985;89:248-58.

22. Fusejima K, Takahara Y, Sudo Y, Murayama H, Masuda Y, Inagaki Y. Comparison of coronary hemodynamics in patients with internal mammary artery and saphenous vein coronary artery bypass grafts: a noninvasive approach using combined two-dimensional and Doppler echocardiography. J Am Coll Cardiol 1990;15:131-9.

23. Nishida H, Endo M, Koyanagi H, Koyanagi T, Nakamura K. Coronary artery bypass grafting with the right gastroepiploic artery and evaluation of flow with transcutaneous Doppler echocardiography. J Thorac Cardiovasc Surg 1994;108:532-8.

24. Calafiore AM, Di Giammarco G, Teodori G, D’Annunzio E, Vitolla G, Fino C, et al. Radial artery and inferior epigastric artery in composite grafts: improved midterm angiographic results. Ann Thorac Surg 1995;60:517-23; discussion 523-4.

25. Kern MJ, Donohue TJ, Aguirre FV, Bach RG, Caracciolo EA, Ofili E, et al. Assessment of angiographically intermediate coronary artery stenosis using the Doppler flowire. Am J Cardiol 1993;71:26D-33D.

26. White CW, Wright CB, Doty DB, Hiratza LF, Eastham CL, Harrison DG, et al. Does visual interpretation of the coronary arteriogram predict the physiologic importance of a coronary stenosis? N Engl J Med 1984;310:819-24.

27. Uren NG, Melin JA, De Bruyne B, Wijns W, Baudhuin T, Camici PG. Relation between myocardial blood flow and the severity of coronary-artery stenosis. N Engl J Med 1994;330:1782-8.

28. Wilson RF, Marcus ML, White CW. Prediction of the physiologic significance of coronary arterial lesions by quantitative lesion geometry in patients with limited coronary artery disease. Circulation 1987;75:723-32.

29. Arnese M, Salustri A, Fioretti PM, Cornel JH, Boersma E, Reijs $\mathrm{AE}$, et al. Quantitative angiographic measurements of isolated left anterior descending coronary artery stenosis: correlation with exercise echocardiography and technetium-99m 2-methoxy isobutyl isonitrile single-photon emission computed tomography. J Am Coll Cardiol 1995;25:1486-91.

\section{Targeted}

The Journal of Thoracic and Cardiovascular Surgery gives you two tables of contents.

The condensed table of contents tells you at a glance what topics and authors are presented each month. The expanded table of contents gives you a brief abstract of each article. You select only those articles of most interest to you for further reading. 